\title{
Laboratório de Computação Aplicada à Educação e Tecnologia Social Avançada (CAEd)
}

\author{
Seiji Isotani ${ }^{1}$, Carla Rodriguez ${ }^{1,2}$, Aparecida M. Zem-Lopes ${ }^{1,3,}$ Leonardo Marques $^{1}$ \\ ${ }^{1}$ Instituto de Ciências Matemáticas e Computação - Universidade de São Paulo \\ Av. Trabalhador São Carlense, 400- 13566-590 - São Carlos - SP - Brasil \\ ${ }^{2}$ Bolsista BJT CNPq - Processo no $300120 / 2014-1$ \\ ${ }^{3}$ Faculdade de Tecnologia de Jahu - Fatec Jahu \\ Rua Frei Galvão, s/n. ${ }^{\circ}$, Jd. Pedro Ometto - Jaú - SP \\ sisotani@icmc.usp.br, \{carlalrodriguez, cida.zem, leobmarques\}@gmail.com
}

O Laboratório de Computação Aplicada à Educação e Tecnologia Social Avançada (CAEd) está inserido na área da "Computação Aplicada", com ênfase em "Informática na Educação". Iniciou suas atividades institucionais em 2012 e, desde então, tem como principal objetivo investigar, desenvolver e aplicar técnicas computacionais na resolução de problemas educacionais. Para alcançar esse objetivo, o CAEd conta com uma equipe multidisciplinar, que atua no desenvolvimento de atividades de ensino, pesquisa e extensão para gerar conhecimento de vanguarda e desenvolver produtos tecnológicos inovadores com potencial de auxiliar o processo de ensino e aprendizagem. São linhas prioritárias de investigação: Tecnologia Educacional; Gamificação na Educação; Sistemas Colaborativos; Sistemas Interativos e Tutores Inteligentes; Ambientes de Aprendizagem Ubíquos; Mineração de Dados Educacionais; Avaliação de Qualidade de Software Educacional baseado em Web Semântica; Computação Afetiva e Web Semântica Social na Educação. Dentro dessas linhas, o CAEd, coordenado pelos professores Ellen F. Barbosa, José C. Maldonado e Seiji Isotani, apoia a oferta formativa em nível da graduação e da pós-graduação e acolhe em seus projetos, atualmente, alunos de iniciação científica, mestrado, doutorado e pesquisadores ao nível de pós-doutorado. Entre outros, os principais projetos de pesquisa em curso têm como objetivo discutir e aprofundar o conhecimento com relação ao uso de ontologias, elementos de gamificação e aspectos afetivos para formação automática de grupos de aprendizagem de alta performance em ambientes colaborativos inteligentes. Projetos em desenvolvimento no CAEd: 1. Formação de Grupos de Aprendizagem Utilizando Elementos Afetivos (CNPq - Processo n ${ }^{\circ}$ 407085/2013-0); 2. Uso de Ontologias e Gamificação para Formação Espontânea de grupos de Aprendizagem (CNPq Processo $\mathrm{n}^{\circ}$ 400481/2013-8); 3. Formação de Grupos de Alta Performance em Ambientes Inteligentes de Aprendizagem Colaborativa $\left(\mathrm{CNPq}\right.$ - Processo $\mathrm{n}^{\mathrm{o}}$ 470757/2013-2). Outros projetos desenvolvidos no laboratório: 4. Plataforma para o desenvolvimento ágil e eficiente de aplicações semânticas (Consórcio WWW); 5. Desenvolvimento e Uso de Sistemas Colaborativos para o Ensino de Matemática com Dispositivos Móveis (CNPq - Processo no 476566/2011-8) e 6. InovaEnComp: Uma Proposta Inovadora para o Ensino Prático em Multidisciplinar de Computação (Edital Pró-Inovalab). 